\title{
Problems and Countermeasures in the Budget Cost Control of Decoration Engineering
}

\author{
Yujia $^{1}$ \\ ${ }^{1}$ Architectural engineering institute, Jiangsu College of Engineering and Technology, Nantong, Jiangsu, China, 226002
}

\begin{abstract}
With the rapid development of China's economy and technology, great progress has been made in all fields. Especially in the field of decoration engineering, great breakthroughs have also been made. The strength of enterprises continues to increase, and the gap between enterprises continues to narrow. In this context, how to strengthen the cost control of decoration enterprises and continuously improve their own strength has become an urgent problem. Based on this, this article carried out the budget analysis of the decoration project and analyzed the problems existing in the enterprise cost budget control. Finally, this paper proposes a series of measures such as unifying the cost budget specifications, continuously improving the project cost budget control system, and strengthening the project cost budget monitoring.
\end{abstract}

\section{Background of the study}

\subsection{Literature review}

Starting from the characteristics of the cost, Zeng Xiaobin analyzed the budget quotation of the decoration project and proposed corresponding solutions to the problems in the budget cost of the decoration project. He believes that the application of decorative cost budget control and various management methods is one of the necessary means for the modern decorative enterprise to continue its development (Zeng, 2016). Zhang Jun and Zhang Shaocheng analyzed the reasons for the easy loss of bridge engineering and put forward specific methods to prevent losses and strengthen bridge cost control from aspects of project implementation process management, quota consumption, and budget preparation methods, and contract terms. They believe that the construction unit should objectively analyze the problems in the bridge construction process, and then carry out a true and objective cost budget (Zhang and Zhang, 2015). Hao Xiaoxia and Hao Dekai deeply discussed the application of construction project budget in construction cost control and believed that the quality of construction project budget has a direct impact on construction cost control. They believe that only by strictly controlling the quality of the project budget work can problems in the construction process be found in time and appropriate treatment plans given in time (Hao and Hao, 2017). Starting from the new green building concept, Wang Qin and Li Lian conducted in-depth research on building cost control and cost budget. The research suggests that the fundamental measure to improve the level of construction projects is to actively formulate and implement effective cost control measures and cost budget management mechanisms. Aiming at the problems in cost control of new green building engineering projects, corresponding management measures were proposed (Wang and $\mathrm{Li}, 2019$ ). Ling Shuhua made an in-depth analysis of the role of engineering budget in the control of engineering cost, and combined with the actual situation of construction engineering budget, proposed targeted solutions to improve the efficiency of engineering budget (Ling, 2016). Li Gangyong and Li Shifang thoroughly studied the role of engineering budget in the control of engineering costs. The study found that budgeters should continuously improve their ability and quality in the cost budget control. In view of the problems arising during the construction process, the budget controller should give a solution ( $\mathrm{Li}$ and $\mathrm{Li}$ ) in a timely manner.

\subsection{Purpose of research}

In recent years, China's decoration industry has developed rapidly and has gradually become a pillar industry of the national economy. However, while the decoration industry maintains rapid development, there are still some problems. Among them, the most obvious problem is project budget control. In the actual construction process of some decoration enterprises, the actual cost of the project often exceeds the budget due to the unreasonable cost budget. In order to reduce corporate costs, some decoration companies can only choose lower-priced, poorquality decoration materials. This problem directly leads to a decline in the quality of decorative works. Therefore, this article analyzes in-depth the problems in the budget control of the decoration project, and proposes specific solutions, hoping to provide a useful reference for the cost control of the decoration company. 


\section{BUDGET ANALYSIS OF DECORATION ENGINEERING}

In the decoration project, to carry out the cost budget, it is necessary to control the cost of each link and process of the project. Taking the decoration of high-rise residential buildings as an example, to carry out the decoration cost budget, it is necessary to take into account the costs incurred in each step of the project construction process (Yin, 2017). At the same time, when making a cost budget, there are other factors that need to be considered, such as whether the construction project is complete and whether the drawings are reviewed accurately.

First of all, when making budget estimates for decoration projects, we need to pay attention to whether all projects have been completed. If some links are omitted in the budget table, then the corresponding expenditure may be increased in subsequent construction. When doing interior decoration, some special situations may be encountered, resulting in increased project costs. For example, if there are cracks in the wall of the decoration, the cracks need to be repaired during the decoration, which will increase the project expenditure accordingly. If this situation is not reflected in the budget, it can also be raised separately during construction on site.

Secondly, when carrying out the project cost budget, the budget staff need to accurately review the construction drawings. Specifically, we must first determine that the construction drawings are accurate, detailed, and complete, which is the basis for making cost estimates. The cost of various materials required for modification needs to be determined according to the specific dimensional data in the drawings. If the drawing is inaccurate, the budget based on the drawing is also inaccurate (Tian, 2015). At the same time, when making a budget, the number of various decorative items in the drawings should be determined.

Finally, in the decoration process and material budget table, the specific decoration size should also be reflected. The decoration company should clearly tell the customers specific decoration technology and materials for the budget quotation. Because in the specific construction process, the price of the same construction material will also vary due to differences in brand and quality. Moreover, different construction methods result in different labor costs. From this point of view, the decoration project cost budget needs to be considered from two aspects, one is to consider from the construction perspective of the project, as shown in Table 1. The second is to consider the social security of employees generated from the project construction, as shown in Table 2.

Table 1. Analysis of Construction Budget Quotation of Decoration Engineering

\begin{tabular}{|c|c|c|}
\hline $\begin{array}{c}\text { Serial } \\
\text { number }\end{array}$ & Expense name & Fees description \\
\hline 1 & $\begin{array}{c}\text { Enterprise } \\
\text { management fee }\end{array}$ & $\begin{array}{c}\text { Labor cost }+ \\
\text { machinery cost }\end{array}$ \\
\hline 2 & Night construction fee & - \\
\hline 3 & $\begin{array}{c}\text { Safe and civilized } \\
\text { construction fee }\end{array}$ & $\begin{array}{c}\text { Labor cost }+ \\
\text { machinery cost }\end{array}$ \\
\hline
\end{tabular}

\begin{tabular}{|c|c|c|}
\hline 4 & $\begin{array}{c}\text { Construction fee in } \\
\text { winter and rainy } \\
\text { season }\end{array}$ & $\begin{array}{c}\text { Labor cost }+ \\
\text { machinery cost }\end{array}$ \\
\hline 5 & $\begin{array}{l}\text { Municipallengineering } \\
\text { interference fee }\end{array}$ & $\begin{array}{c}\text { Labor cost }+ \\
\text { machinery cost }\end{array}$ \\
\hline 6 & $\begin{array}{c}\text { Secondary handling } \\
\text { fee }\end{array}$ & - \\
\hline 7 & Other project costs & - \\
\hline
\end{tabular}

Table 2. Analysis of Quotations for Social Security Budget of Staff

\begin{tabular}{|c|c|c|}
\hline $\begin{array}{c}\text { Serial } \\
\text { number }\end{array}$ & Expense name & Fees description \\
\hline 1 & Pension & $\begin{array}{c}\text { Labor cost }+ \\
\text { machinery cost }\end{array}$ \\
\hline 2 & Medical insurance & $\begin{array}{c}\text { Labor cost }+ \\
\text { machinery cost }\end{array}$ \\
\hline 3 & Injury insurance & $\begin{array}{c}\text { Labor cost }+ \\
\text { machinery cost }\end{array}$ \\
\hline 4 & Maternity Insurance & $\begin{array}{c}\text { Labor cost }+ \\
\text { machinery cost }\end{array}$ \\
\hline 5 & $\begin{array}{c}\text { Unemployment } \\
\text { insurance }\end{array}$ & $\begin{array}{c}\text { Labor cost }+ \\
\text { machinery cost }\end{array}$ \\
\hline 6 & $\begin{array}{c}\text { Injury insurance other } \\
\text { than hazardous work }\end{array}$ & $\begin{array}{c}\text { Labor cost }+ \\
\text { machinery cost }\end{array}$ \\
\hline 7 & \multicolumn{2}{|c}{ Housing fund } \\
\hline
\end{tabular}

\section{PROBLEMS EXISTING IN BUDGET CONTROL OF DECORATION ENGINEERING}

\subsection{Lack of a unified budget cost specification}

At the present stage, when budgeting for decoration projects, there is still a lack of uniform budget specifications. Specifically, managers who perform budget analysis on decoration projects have not actually applied specific calculation methods to budget control. In the development of specific work, due to the unscientific use method, the calculated budget cost data is greatly different from the actual needs. This has a large adverse impact on the control of the entire engineering cost. In the budget cost control, the cost budget personnel can only make a pricing evaluation on limited decorative materials, and cannot accurately grasp the cost of the grafting materials in the decoration process. This makes it difficult to accurately estimate the overall cost of the decoration project. In the actual implementation of the decoration project, there will be a lot of indirect costs. If the cost budgeter cannot estimate these indirect costs, it is difficult to accurately estimate the budgeted cost of the decoration project.

\subsection{Weak budget supervision}

In the decoration project, the construction cost budget requires corresponding supervision and management. However, at present, in the specific cost budget of decoration projects, the overall supervision is weak. This issue is also an important factor that affects the accuracy of the construction cost budget of the decoration project. 
In specific work, the state's primary regulatory authority did not evaluate specific engineering projects before approving the budget. Regarding the design situation, feasibility and project approval of engineering projects, relevant departments lack strict inspection links and demonstration links. At the same time, relevant departments have not strictly controlled construction drawings and project designs. In the case where these issues are not empirical, many decoration projects have already been approved and appropriated by relevant departments. In addition, in the case that the project cost budget is significantly exceeded, the relevant regulatory authorities have not thoroughly investigated the responsibility of the project leader, and have not conducted an in-depth investigation of the actual situation. Under this circumstance, project approving personnel approve and appropriate at will, which leads to the continuous increase of the cost budget of the decoration project, showing a state of the false budget.

\subsection{Budget cost control system is not yet perfect}

In recent years, the decoration project has developed rapidly, but it still lacks a relatively perfect budget cost control system. The decoration company attaches great importance to the construction management of decoration but has not invested the corresponding financial and material resources for the control of the cost budget. In other words, the decoration company does not pay enough attention to this part of the cost budget. Therefore, in the cost budget control, a relatively complete management system has not been established. The lack of a complete budget cost control system leads to some loopholes and shortcomings in the actual budget of a project. At present, some senior managers of decoration companies still lack complete knowledge of cost control. At the same time, they have a certain cognitive bias on cost control. This leads to the lack of a mature cost budget management system for decoration companies. Because managers have certain cognitive errors in the cost budget, it is difficult to manage the cost control from a global perspective. In the decoration project, scientific coordination cannot be achieved, and it is difficult to quickly respond to and adjust to unexpected situations. The existence of these problems will cause a lot of waste on their own, and will also adversely affect the overall progress of the decoration project.

\subsection{Lack of professional cost budget talents}

In the development of any industry, professional talents are indispensable. Regardless of the job, the level of work and quality of the personnel will have a decisive impact on the overall work. Of course, decoration works are no exception. In budget cost control, the professional quality of the cost of budgeting personnel is very critical. The professional quality of the budget personnel has a great influence on the rationality and accuracy of the project cost budget. It is no exaggeration to say that the professional level of budget personnel is a key factor affecting the accuracy of cost. But at this stage, many decoration companies in China, especially some small and medium-sized decoration companies, have not invested enough energy in the construction budget. Even in some decoration companies, no special cost budget department has been set up. In some decoration projects, many enterprises just set up a temporary department to carry out the overall construction cost budget. Among them, some cost budget personnel do not have an in-depth understanding of the market situation, nor do they possess relevant professional knowledge and professional qualities. This has caused some decoration companies to have low internal cost budgets and poor levels, making it difficult to play the practical role of budget management.

\section{COUNTERMEASURES OF BUDGET CONTROL OF DECORATION ENGINEERING}

\subsection{Unified cost budget specifications}

In the development process of China's decoration industry, many companies have begun to integrate with the international, gradually develop international trade and open up international markets. Therefore, when carrying out the management of the decoration project budget cost control, it is necessary to unify the cost budget of the decoration industry and establish a standard cost specification. Control and adjust the cost budget of the decoration industry, especially the specific behavior of the relevant staff must be unified and standardized. At the same time, in the actual operation process, a unified budget cost method and measures should be established. Relevant staff should carry out the corresponding engineering cost budgeting work in accordance with the norms and standards. By establishing a unified budget specification, the accuracy and quality of the decoration project cost budget are improved. In this way, the decoration project can be completed on time, the effect of the budget cost control can be successfully realized, and it is also conducive to the establishment of the core competitiveness of the decoration enterprise.

\subsection{Continuously improving the engineering cost budget control system}

If we want to effectively promote the engineering cost budget control of decoration enterprises, we must constantly improve the engineering cost budget control system. A complete cost budget control system can effectively ensure the effect of cost budget control, and it can also not improve the efficiency of enterprise cost budget work. In the specific cost budget control, the enterprise should continuously strengthen the coordination and cooperation between its internal departments, and promote the exchange and communication between various departments within the enterprise. The responsibilities and tasks of each department should be clarified. At the same time, the construction department and the design department should communicate in a timely manner, be responsible for their 
specific work, cooperate with the other department's work, and strengthen the contact between the departments. Through continuous improvement of the construction cost budget control system, the work among various departments is reasonably arranged, thereby improving the work efficiency of each department.

\subsection{Strengthening engineering cost budget monitoring}

In view of the current weak budget supervision, related departments and enterprises should strengthen the budget monitoring of decoration projects. On the one hand, decoration companies should strengthen control over project materials. With the continuous development of the market economy, the value and materials of materials used in decoration projects are constantly changing. This is also a major reason for inaccurate budgets and customer requirements. Therefore, when quoting for customers, enterprises should strictly control the price of decorative materials. According to the actual decoration situation, choose the appropriate decoration material. In addition, companies should try to choose relatively environmentally friendly materials, which not only controls decoration costs but also protects the building's living environment. On the other hand, relevant supervisory departments should strengthen the supervision of decoration enterprise projects. During the construction process of the project, the relevant supervisory authority should monitor the project's machinery use, labor distribution, material purchase and consumption, and other funds usage. On the premise of ensuring the requirements of customers, strictly monitor the problems of misreporting the price of materials, and avoid the situation of falsely high budgets, so as to achieve reasonable control of the budget cost of decoration projects.

\subsection{Improving the professional level of enterprise cost budget personnel}

In the actual budget cost process, the professional level of relevant personnel is an important factor affecting the accuracy of the cost budget. Therefore, enterprises should attach great importance to the project cost budget, continuously improve the professional level of relevant staff of the enterprise, and then build a professional cost budget team. First, we must control the professional quality of talents from the source. In the recruitment process, enterprises should strictly evaluate the professional ability and comprehensive quality of the recruited personnel. While examining the candidate's professional ability, he must also conduct a strict assessment of his professional ethics. Only when the professional quality and professional ethics have passed the recruitment assessment can personnel be recruited. Second, pre-job training for the cost of budget staff recruited. After recruiting relevant talents, enterprises should provide them with pre-job training so that newly recruited staff fully understand their job responsibilities, be familiar with the company's operating processes and operating specifications, and avoid some low-level errors in their work. Third, for employees who have already joined the company, the company should increase some cost budget training to encourage employees to continuously improve their professional capabilities and comprehensive quality, and then better respond to unexpected situations at work.

\section{Acknowledgments}

Provincial Training Program: enterprise practice of young teachers (No: 2020qysjpx066)

Project Name: Jiangsu College of Engineering and $\mathrm{T}$ echnology of Engineering Science and Technology Pr oject -- Key Technology Research on Trenchless Rep air of Municipal Pipeline Network Based on UV Insitu Curing Method (GYKY/2020/8)

\section{REFERENCES}

1. Zeng X.B. (2016). Discussion on the Budget Quotation Analysis and Cost Characteristics of Decoration Engineering, Modern Decor (Theoretical), 32 (3), 23-24.

2. Zhang J., Zhang S.C. (2015). Thoughts on Cost Control of Expressway Bridge Engineering, Road Machinery \& Construction Mechanization, 32 (2), 78-80.

3. Hao X.X., Hao D.K. (2017). The Role of Construction Engineering Budget in Engineering Cost Control, Global Market, 24 (5), 185-185.

4. Wang Q., Li L. (2019). Analysis of New Green Building Engineering Cost Budget and Cost Control, Building Materials and Decoration, 15 (16), 145-146.

5. Ling S.H. (2016). The Importance of Construction Engineering Budget in Engineering Cost Control, Building Materials Development Guide, 38 (23), 250251.

6. Li G.Y., Li S.F. (2016). Discussion on the Role of Construction Engineering Budget in Engineering Cost Control, Global Market, 23 (14), 237-237.

7. Yin J. (2017). Research on Pre-Settlement Audit of Building Decoration Engineering. Jiangxi Building Materials, 37 (5), 237-238.

8. Tian Y. (2015). Control and Management of Budget and Final Accounts for Construction Engineering, Northern Economy and Trade, 35 (4), 188-189. 